\title{
Development of Religious Education to Spread the Culture of Dialogue within Saudi Universities: Ethnographic Case Study
}

\author{
Adel Abubaker Bawazeer \\ University of Stirling, Scotland \\ King Abdulaziz University, Jeddah, Saudi Arabia
}

\begin{abstract}
This project investigates how the culture of dialogue among university students might be improved by developing the university textbook of their course in religious education. Dialogue in Saudi Arabia has in the last decade become more important as an issue and the regime is seeking to improve the culture of the people through dialogue. This study seeks to contribute to this plan. From the huge number of university courses in Saudi Arabia, this study has chosen one as a case study with its textbook. The first step in doing so is to understand the present culture of dialogue within Saudi society by adopting the methodology of an ethnographic instrumental case study. To this end, teachers and students within the university were contacted as well as others outside who are interested in dialogue. At the same time, various documents relating to the culture of dialogue in Saudi Arabia were analysed, in order to discover the teachers' and students' behaviours vis-à-vis dialogue and the meaning behind these behaviours by classroom observations of male and female classes.
\end{abstract}

\section{Introduction}

For more than 10 years, Saudi Arabia has been considering the very worthwhile project of spreading the culture and skills of dialogue amongst its people [21]. A range of factors have encouraged the government in this. In 2003, the King Abdulaziz Centre for National Dialogue was established by the Saudi government. The principal aim of this Centre is to spread the culture of dialogue and to promote national unity and the public interest illuminated by the light of Islam [21].

Different perspectives have made the concept of dialogue varied and complex, as are its forms in practice. The major image of dialogue is that of conversation, but some imagine it as a synonym for debate, discussion and argumentation; however, even in Arabic and Islamic literature, the converse does not hold good. Still, it can be said that all these synonyms are aspects of dialogue [27]. Its main function is to permit the exchange of ideas and opinions, share information and experiences, or analyse assumptions and provide solutions to particular problems. When dialogue is quite free, it leads the way to a kind of thinking without tension and can open people's minds to other opinions [26]. Theoretically, dialogue depends, for Muslims, on innate dispositions, social interactions, interfaith connections and respect for diversity. Dialogue in Islam is not undertaken simply to help resolve conflicts between groups; this is only one of its expected results. However, dialogue is a major part of Islamic culture, so Muslims look upon it as a human interaction, one of the natural proclivities of everyday life [22].

Some theoretical views hold that dialogue can take a philosophical pattern. Bakhtin's was that of a philosopher who theorised that dialogue depends on its component linguistics, phonetics and semantics and that it is important to understand the whole context of dialogue and the factors which affect it. He believed that these factors are the irreducible social and historical events that relate to human beings, together with their ideology, culture and cognitive understanding of the meanings of words in the process of communication [23][30][31].

Education is increasingly a fundamentally important factor in the development of individuals. All societies consider education to be a tool for the creation of wealth and happiness, but learning is also the main contributor to the building of an individual's capacity to be more effective in all areas of their future life. Higher education in Saudi Arabia aims to prepare qualified and competent citizens to perform their duties in the service of their country for the progress of their nation; it offers, for example, training services and reorientation courses to enable students who are already working to keep pace with new developments [29]. However, for cultural and political reasons, academic freedom in Saudi universities is limited [2]. It is believed that engaging in dialogue by means of the university textbook may achieve the aims of the policy and help solve the problem of academic freedom.

Textbooks are generally deemed to be an integral part of the education system, with the textbook often being a principal source of information in a university syllabus. In the Saudi Arabian university system, the university textbook is considered part of the educational policy and is therefore something 
that both teachers and students must follow, meaning that it is one of the most important tools for the introduction of knowledge and skills. This means that a university textbook should aim to go beyond the university "by giving attention to current developments in society including the use of media (newspaper, television and radio) and by setting assignments which address societal problems" [5:293].

Classrooms, at the same time, can develop dialogue skills, giving the students a chance to express their views, increase their motivation to interact with others, exchange ideas and engage in conversations [1]. These initiatives suggest that students engaging in the practices of dialogue will in turn develop more open-ended forms of thinking [25]. In this regard, the role of dialogue in the exchange of knowledge has gradually become more important, implying a new relationship between teachers and students in a social and cooperative environment [17] [18].

\section{Aims}

In my experience of teaching classes in Islamic Education and supervising the students who specialise in it as part of their teacher-training course in the Faculty of Education at King Abdulaziz University in Jeddah, I have noted that the outline of the syllabus or module is always based on one reference book, to which all the teachers and students should adhere; only a few teachers are skilled in the teaching methods which promote dialogue or give the students a chance to discuss their queries. These observations are supported by the results of studies showing that Religious Education teachers rarely allow learners enough opportunities to speak or discuss in the classroom [4]. Another study shows that there is increasingly less room in the content of high school textbooks in Hadith and Islamic culture for developing the cognitive aspect of a creative renewal of tradition or the ability to enter into dialogue and offer constructive criticism [3]. In published research, a study of Saudi culture finds only a weak to semi-strong capacity to use dialogue as a means of communication between people [20]. This means that many people need more training and education before they can engage in dialogue activities.

When I tried to find university-level books that had been written to satisfy the popular and official demand for dialogue, I could discover none. The present study may therefore be the first to do so and could serve as a starting point from which to suggest the kinds of activity to include in a university textbook on Islamic culture that would meet religious, intellectual and security needs, as well as the expectations of the state and the perceived needs of society.
In this project, the principal aim is to discover how religious education textbooks can be developed in Saudi universities so as to promote the capacity for dialogue among students, in order to attain the aim of spreading dialogue as a cultural element in the country.. From this perspective, dialogue is basically a cultural and social activity seeking to reconcile differences between people. For this reason the various attitudes to dialogue in Saudi society should be understood. In the present study, understanding is sought through ethnographic research into people's behaviour and their background familiarity with dialogue. Students and academic staff are intended as the participants in this study.

\section{Methodology}

The project applies a Qualitative and Ethnographical Instrumental Case Study methodology, despite the criticism of qualitative approaches that they can be over-subjective [10], lacking in reliability and validity [32] and time-consuming [9]. This is because qualitative research serves several purposes in the project; for example, it allows testing, theory generation, the creation of key concepts, description and reporting [11].

While dialogue is considered the core of this study, describing and investigating the community culture in Saudi universities may be seen as the essential target. Therefore, ethnographic research is used, not merely to study and enquire into the behaviour and culture of a society [12], but also to understand the meanings behind such behaviours [28]. This is why Hammersley and Atkinson [19] and Punch [28] emphasise that ethnographic research is a paradigm of naturalistic research. Thus, a case study can be a method of naturalistic research, which investigates a specific phenomenon within a particular society [6] [14].

It seems that the topic of dialogue, as a cultural area, and higher education, as a location for studying it, are aspects of a realistic or naturalistic field. In this case, the methods are qualitative and the present study uses semi structured interviews, document analysis and field notes from observations of university classes.

Case study research is concentrated on a particular, singular and unique case; a single community, single school, organization or person [10] [33] [34]. One of the features of case study research is that it reports its relation with "the real-life, complex dynamic and unfolding interaction of events, human relationships and other factors in a unique instance" [11: 289]. The aim of a case study is to understand social phenomena by studying events as they occur, in order to see what things look like from the different perspectives of "powerless and voiceless participants and the interaction between them" [13]. 
A case study strategy to be used in educational research was constructed in [8] by Bassey. He suggests that a case study is 'a prime strategy for developing educational theory which illuminates educational policy and enhances educational practice' [8:3]. He identifies three types of educational case study: theory-seeking and theorytesting; story-telling and picture-drawing; and evaluative. This research project, in Bassey's definition, is a 'theory-testing' case study, among the “... particular studies of general issues - aiming to lead to fuzzy propositions (more tentative) or fuzzy generalisations (less tentative) and conveying these, their context and the evidence leading them to interested audiences" [8:58].

In the scheme of possible case study strategies, my project is focused on a single and particular case. It concentrates on one organization; on one educational module, Islamic Culture; and evaluates the module's achievement in one area, that of dialogue. This concept is treated as a framework for human interactions in the dynamic of everyday life, in which, as a result of these interactions, different phenomena may appear. A case study can discern in some depth the diversity of the participants' perspectives, and hence of their reasoning.

Supported by Bassey's design [8] of the types of case study strategy in educational research, this research looks for educational practices in the classrooms where this educational project was undertaken. But none of the three types of case study adequately and accurately describes what I want to do in the present research. This does not seek to test a theory, but to collect and understand the practical perceptions of the case held by the participants, at the same time evaluating different practical ideas.

Hence Stake's identification of three types of case study [34] may, in my opinion, be more relevant than Bassey's to the present project. His three types are: intrinsic case studies, to understand a particular case in question; instrumental case studies, for gaining a deeper vision of a theory or an issue after examining a single case; and collective case studies, for gaining a full conceptualisation from different studies illustrating a single case. This may help create new ideas for developing the university textbook. In addition, we may be able to understand different theories in the area from reviewing studies of dialogue and of curriculum design to show how to translate theory into practice in describing the relations between students and teachers, or among other groups of people as they engage in dialogue.

Case studies are not immune from criticism, but they also have their strengths. Their results cannot be generalised to a population, and they may be affected by the researcher's bias, they can be time consuming and it is difficult to use them in summarising and developing propositions. However, their strengths are that they can provide detailed information, new suggestions for research and new in-depth perspectives from which high quality suggestions can be drawn [15] [24].

To reduce possible anxiety in using a case study model, Flyvbjerg reports one of its benefits in research:

"that human behaviour cannot be meaningfully understood as simply the rule-governed acts found at the lowest levels of the learning process and in much theory" [15:223].

Bassey [8] also writes that case studies can produce fuzzy generalizations, which consist of "qualified generalization, carrying the idea of possibility but no certainty $^{\text {ee }}$ [10:46]. Flyvbjerg [15] emphasises that generalisations can be derived even when only a single case underlies them.

This debate about the shortcomings of the case study may remain when we are thinking about research validity. Flick [14] suggests that in qualitative research the validity of the outcomes is directly linked to the design of the research. Here, the case study is a comprehensive strategy and method which covers the research design and data collection; it can include two or more methods, approaches to data analysis and ways of connecting the items of information that come from different methods of data collection and analysing [10] [36].

In particular, the methods of collecting data in the present research were either: a) individual face-toface semi-structured interviews with Saudi Government officials, to understand the situation of dialogue in the culture of Saudi Arabia; or b) semistructured interviews by telephone with the male and female teachers and students who teach and attend the "Islamic Culture" module at the university where the case study is based. In this method, questions were asked in semi-structured interviews to find how far dialogue was applied in classrooms and in the educational content of Islamic Studies; and to identify recommendations for adjustments to the university textbook that would familiarize students with the best conditions for dialogue and equip them to engage in it. Using semi-structured questions made the interviews and discussions more flexible for the interviewees and enabled the interviewer to react to new and unexpected responses from participants.

In addition, observations within the classrooms where this subject was taught were applied. The researcher engaged with teachers and students in the lessons by asking questions and introducing valid points for discussion. In addition, a number of documents touching the issue of dialogue in Saudi Arabia were analysed. The documents were collected from a variety of sources at the King Abdulaziz Centre for National Dialogue in Saudi Arabia; journal articles, dialogue workshop papers, dialogue conference papers, dialogue magazines, and public opinion polls. The semi-structured interviews with 
government officials sought to understand the situation, social culture and public understanding of the culture of dialogue and to interpret different behaviours and the meaning of these behaviours within the community in general and the university classrooms in particular.

Out of the 25 universities in Saudi Arabia where a case study could be conducted, this research took place in Saudi University. In addition, from the textbooks at the four levels of Islamic Studies (SLM101, SLM201, SLM301 and SLM401), each containing approximately four chapters and eight units, the specific sample that was chosen for inclusion in this study was the book for level three (SLM301).

The textbook for the first level of this curriculum concentrates on the theoretical foundations of Islamic culture that are linked with Islamic doctrine and compulsory worship. In the second level, the textbook addresses the sources of Islamic jurisprudence such as the Holy Qur'an and Sunnah. The third part concentrates on the sphere of social practice, including Islamic morality in regard to the correct way to deal with others in the same or from another society. The textbook for the fourth level focuses on the value of work and professional ethics in Islamic culture. The textbook for the third level, then, seemed to be most appropriate for spreading the practice of dialogue as far as possible over the nation, as well as for addressing universal and social issues.

The chosen textbook comprises three chapters: the first is on the family system in Islam; the second concerns the Islamic social system; and the third covers Islam and some contemporary issues [7]. These topics are closely related to everyday life; teachers and students were familiar with them and could deal with them directly. This was thought to be helpful in encouraging both groups to practise dialogue.

When the interview and discussion process had finished, coding was used to categorise, label and analyse the responses. In the analysis, the data were coded by giving "a name or label ... to a piece of text that contains an idea or a piece of information" [11:559]. It has been claimed that written material is relatively easy to code and categorise [16]. In this study, the transcripts that are coded and analysed will derive from both interviews with university teachers and focus discussion groups. Following the data analysis, a final report was written and linked to the results of the data analysis and the literature review. From this, some final recommendations were inferred.

\section{Conclusion}

From the above, we can agree that dialogue is a concept of interaction between people who may be different in religion, ideology, culture and/or language. By its means the people in one society or different societies can exchange knowledge and experiences in order to gain a deeper integration, one which is constructed on the principles of free thinking, peace and the preservation of the signs of civilisation. However, the situation in the Kingdom of Saudi Arabia is slightly different. This is because Saudi Arabia is a 'mono-cultural society' in which the population follows one religion, uses one language, and has one government. Hence, the primary question is why dialogue is so important in this kind of society. In order to answer this question, it is necessary to understand what pluralism means in Saudi society, and university is a case study which it is hoped will help in the attempt. The general understanding is that pluralism or diversities can be identified through the various understandings of Islamic regulations and the various possible methods of implementing them.

Therefore, this project sought to investigate and report on the implementation of the dialogue and its culture in the educational context of a specific university textbook on religious education. Many aspects were addressed that relate to the culture of dialogue between the academic staff and students within the Saudi university, such as the concept of dialogue, the community's values and its virtues, the nature of Saudi society, the university textbooks used for religious education, and the university environment. The initial indicator showed that it was possible to develop the educational textbook to accommodate the culture of dialogue. But the main point was to find how this should be done in the context of Saudi culture, its higher education policy, the university educational activities and regulations, and the relations between the academic staff and students within the classrooms.

\section{References}

[1] Abdul Hameed, J. (2000) Teaching and Learning Strategies, Cairo, Dar Arab Thought.

[2] Alamri, M. Higher Education in Saudi Arabia, Ministry of Higher Education, Saudi Arabia, 2012, (online), $\quad$ www.nabusinesspress.com/JHETP/AlamriWeb11-4.pdf, Accessed June 2013.

[3] Al Dousary, A. (2004) The Role of Hadith and Islamic Culture Book Contents in Developing Positive Trends to the Third Class High Secondary School Students in the Eastern Region, Unpublished $\mathrm{PhD}$ Thesis, Faculty of Education, Makkah, Um Al Qura University.

[4] Al Malki, A. (2004) Jurisprudence of Teaching and Education and the Extent of its Uses in Teaching Islamic Instruction in the High Secondary Grade in Saudi Arabia. Unpublished PhD Thesis, Faculty of Education, Makkah, Um Al Qura University.

[5] Amankwaa, K, Hammonda, H. and Kofigahb, F. "What is in a Textbook? Investigating the language and literacy learning principles of the "Gateway to 
English' textbook series", Pedagogy, Culture \& Society, 2011, 19 (2), pp 291-310.

[6] Aresnault, N. and Anderson, G. (1998) 'Qualitative Research' In G. Anderson and N Aresnault, Fundamentals of Educational Research (second edition). London: Routledge Farmer, 35-113.

[7] Ballamash, F., Azher, H. and Obaid, F. (2011) Islamic Culture (part three), King Abdulaziz University, Jeddah, Dar Hafiz.

[8] Bassey, M. (1999). Case study research in educational settings. Maidenhead: OUP.

[9] Berg, B., (2007) Qualitative Research Methods for the Social Sciences, Boston Pearson

[10] Bryman, A. (2008) Social Research Methods, Oxford, Oxford University Press.

[11] Cohen, L., Manion, L. and Morrison, K. (2011) Research Methods in Education, Oxon, Routledge.

[12] Dobbert, M and Kurth-Schai, R. (1992) 'Systematic Ethnography: toward an evolutionary science of education and culture' In M. LeCompet, W. L. Millroy andJ. Preissle (Eds) The Handbook of Qualitative Research in Education. London: Academic Press, 93-160.

[13] Feagin, J., Orum, A., \& Sjoberg, G. (1991) A Case for Case Study. Chapel Hill, North Carolina, University of North Carolina Press.

[14] Flick, U. (2006) An Introduction to Qualitative Research (3rd edn), London, Sage Publications Ltd.

[15] Flyvbjerg, B. (2006) 'Five Misunderstandings about Case-Study Research'. Qualitative Enquiry, 12 (2), pp 219-245.

[16] Gibbs, G. (2007) Analyzing Qualitative Data, London, SAGA.

[17] Grudens-Schuck, N. (2003) 'No Beginners: teaching participation at the graduate level', PLA Notes, 48 (12), pp 11-14

[18] Haggis, T. (2006) 'Pedagogies for Diversity: retaining critical challenge amidst fears of 'dumbing down', Studies in Higher Education, 31 (5), pp 521535.

[19] Hammersly, M. and Atkinson, P. (1995) 'The Politics of Social Research', London: Sage.

[20] King Abdulaziz Centre for National Dialogue (2005) 'Dialogue Culture in Saudi project and a literature review'. Pedagogic Research in Maximising Education, 3 (2), pp. 17-26.

[21] King Abdulaziz Centre of National Dialogue (2014), (online), Available http //www.kacnd.org/eng/, Accessed February 2014.

[22] Kurucan, A. and Erol, M (2012) Dialogue in Islam: Qur'an - Sunnah - History, Dialogue Society, London.

[23] Kwon, G. (2013) Bakhtin and the Dialogic Approach, (online), Available http://www.scribd.com/doc/137926116/Bakhtin-andthe-Dialogic-Approach, Accessed June 2013.

[24] McLeod, S. A. (2008). Case Study Method. (online), Available http://www.simplypsychology.org/casestudy.html, Accessed February 2014.

[25] Nicholas, C. and Bertram, C. (2001) Theory and Research on Teaching as Dialogue, In Virginia Richardson (Ed.), Handbook of research on teaching, 4th Edition (pp. 1102-1121), Washington DC, American Educational Research Association.

[26] Pearce, W. \& Kimberly A. (2004). Taking a communication perspective on dialogue; in
Anderson, Rob; Leslie A. Baxter; \& Kenneth N. Cissna, (Eds.), Dialogue. Theorizing Difference in Communication Studies, pp.39-56, Thousand Oaks, California, Sage Publications.

[27] Pieczka, M. Wood, W. and Escobar, O. (2010) Dialogue in Scotland? A forum with communication practitioners, School of Arts and Social Sciences, Centre for Dialogue, Working Paper 2, Edinburgh, Queen Margaret University.

[28] Punch, K. F. (2003) Survey Research: The Basics. London: Sage.

[29] Saleh, M. "Development of Higher Education in Saudi Arabia", Higher Education, 1986, 15, pp 1723.

[30] Shotter, J. (2008) 'Dialogism and Polyphony in Organizing Theorizing in Organization Studies: Action guiding anticipations and the continuous creation of novelty', Organization Studies, 29 (4), pp 501-524.

[31] Sidorkin, A. (1996) An Ontological Understanding of Dialogue in Education, Doctor of Philosophy Thesis, University of Washington. (online), Available on http://sidorkin.net/pdf/dis.pdf, Accessed July 2013.

[32] Silverman, D. (2006) Interpreting Qualitative Data, SAGE Los Angeles.

[33] Simons, H. (2009) Case Study Research in Practice. London, SAGE.

[34] Stake, R. (1994) Case Study, In N. K. Denzin and Y. S. Lincoln (Eds.) Handbook Qualitative Research, London, SAGE.

[35] Stake, R. (1995) The Art of Case Study Research, Thousand Oaks, Calif, SAGE.

[36] Yin, R. (2003) Case Study Research: Design and Methods (3rd edn) Thousand Oaks, Calif, SAGE. 